\title{
New records for \\ Parasteatoda tepidariorum (C.L. Koch, 1841) (Araneae: Theridiidae) in Southern Chile
}

\author{
Nuevos registros de Parasteatoda tepidariorum \\ (C. L. Koch, 1841) (Araneae: Theridiidae) en el sur de Chile
}

Eduardo I. Faúndez ${ }^{1,2}$ \& Fernando Téllez ${ }^{3}$

Theridiidae is one of the most diverse families of spiders, including 2472 species classified in 124 genera (World Spider Catalog, 2016). Spiders on this family are widely known for having several synanthropic and cosmopolitan species (Levi, 1967a); as well as species of medical importance (Faúndez \& Tellez, 2016b).

Parasteatoda tepidariorum (C.L. Koch, 1841) (Figs. 1-2), is a cosmopolitan species of Theriididae, which is usually associated with humans (Levi, 1955, 1967a). This species is believed to have a tropical South American origin, because is the only place on which it has been found unassociated with humans (Levi, 1967a). This species has neurotoxic venom; however its bite has been described as considerably less severe than black widow bite effects (Isbister \& Gray, 2003).

In Chile, there is little information on this species, and it has been recorded from Antofagasta to Santiago (Taucare-Ríos et al. 2013). The purpose of this contribution is to provide new record for this species from Southern Chile:

Material examined: CHILE: Araucanía Region, Temuco, 11-V-2016, leg. F. Téllez 1ð19; same data, 09-X-2016, 1 juvenile; same data, 16X-2016 1§1․ (In F. Téllez collection). Los Lagos Region, Osorno, 21-IX-2016, leg. J. Cáceres $1{ }^{\lambda} 2$ 우 (In Departmento de Zoología Médica, CEBCh collection).

In addition to these specimens preserved in collections, there are numerous observations made in field in both regions since 2014. Common places in which the specimens were found included the outside walls of homes (Fig. 1), laundries, and sinks. Also, three specimens are currently maintained alive for observational purposes in Temuco city.

\section{COMMENTS}

This species was recorded from Chile by (Levi, 1967b) From Antofagasta, Tal Tal, and Santiago. Levi (1967b) wrote that specimens were collected in Villarrica (Araucanía Region). However, this author did not include that locality in the checklist section of his paper. Therefore, leaving unclear $P$. tepidariorum was established that far south, or these were just occasional records. Lately, Sedgwick (1973) reported it from Pampilla, Coquimbo. Finally, TaucareRíos et al. (2013) indicated that this species is distributed from Antofagasta to Santiago. The records here provided confirm the presence of this species in the Araucanía Region and extends its distribution southwards to Los Lagos Region.

Entomology Department, School of Natural Resource Sciences, North Dakota State University, Dept. 7650, P.O. Box 6050; Fargo, ND, USA.

$\gg$ ed.faundez@gmail.com

2 Departamento de Zoología Médica, Centro de Estudios en Biodiversidad (CEBCh), Magallanes, 1979, Osorno, CHILE.

3 Centro de Salud Familiar Nueva Imperial, Gorostiaga 258, Nueva Imperial, CHILE. 
Puerto Montt becomes the southernmost record for this species in Chile, and it also becomes the first time in which this species reach the northern edge of Patagonia.

This species is variable in size and coloration (e.g. Figs. 1-2). However, the genitalia is very constant (Levi, 1955). The Chilean specimens seem to follow this pattern too, being consistent among material examined (Figs. 3, 4, 5). Therefore, genitalia examination is desirable to confirm the species identity. This issue becomes especially important as this species can bite humans. Faúndez (2009) indicated that several spider bite cases in Chile are wrongly assigned to other species, especially to black widows in the case of theridiids. However, recent data has shown that other theridiids (i.e. not just black widows) have been also recorded biting humans in Chile (Faúndez \& Tellez, 2016a, b). Thus, with more accurate identifications, these bites cases can be correctly assigned.

Although the bite of this species is relative less severe compared to other theridiids, it has
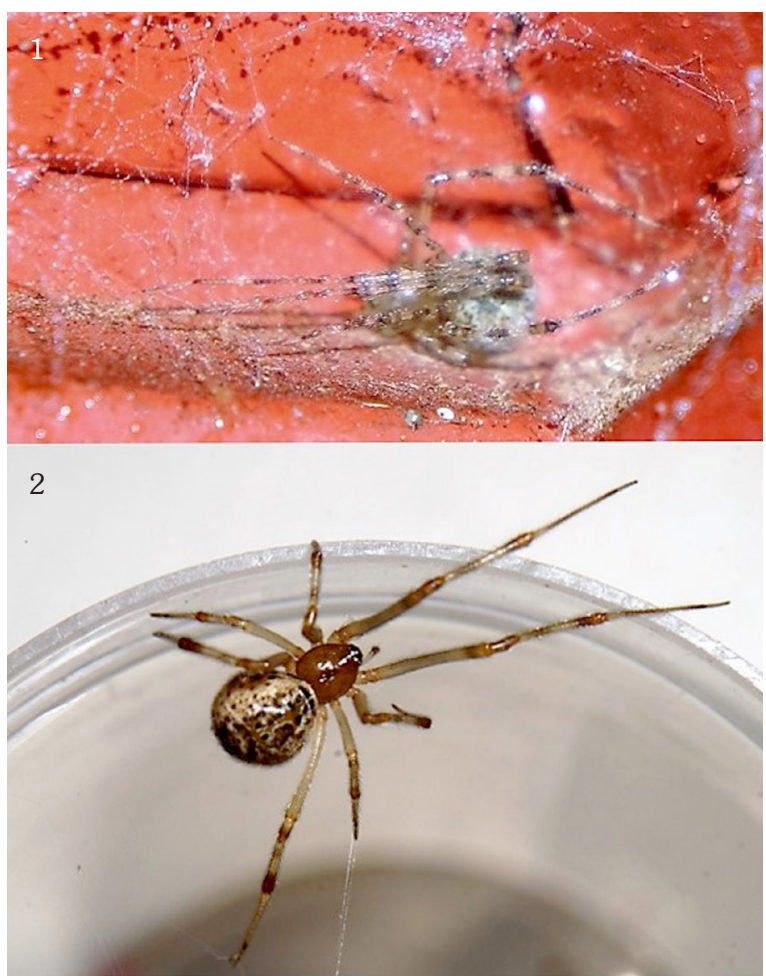

Figs. 1-2. Parasteatoda tepidariorum, 1. Live female specimen from Pto. Montt (05-12-2014); 2. Live female specimen from rearing (Temuco, 04-01-2016).
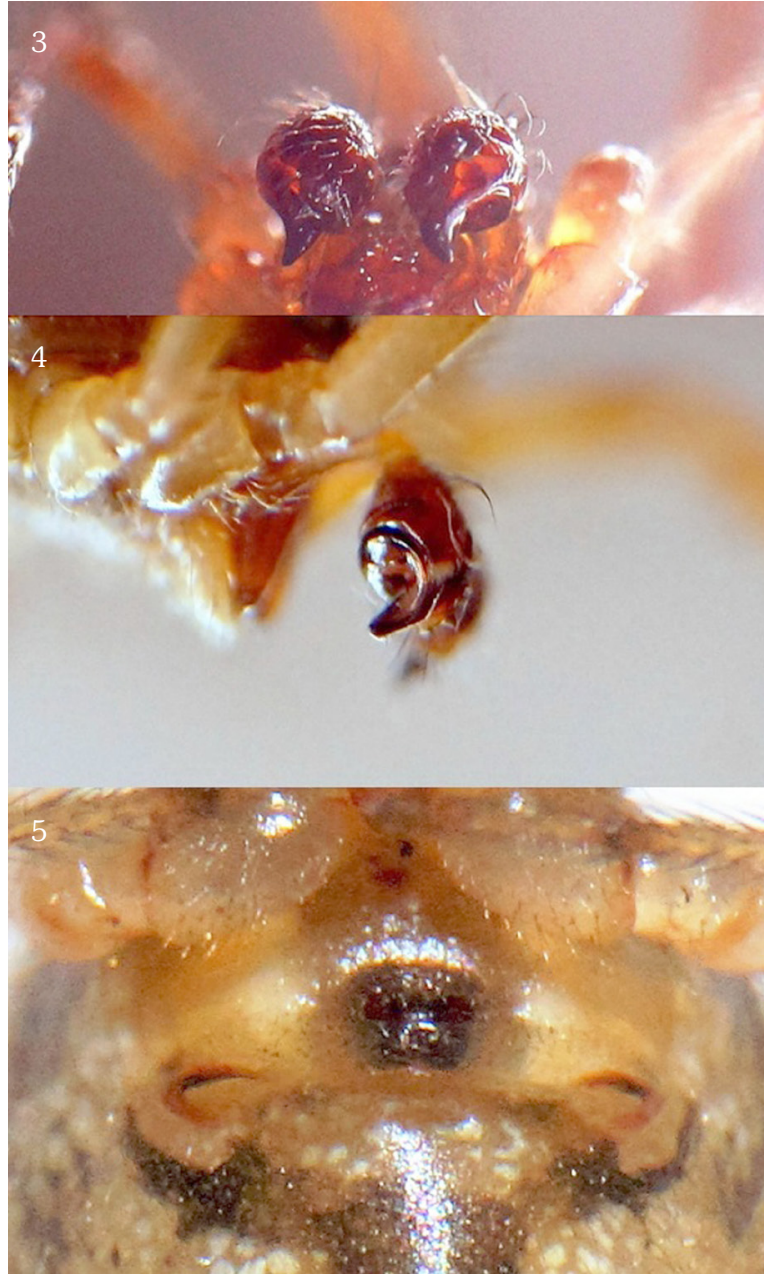

Figs. 3-5. Genitalia of Parasteatoda tepidariorum, 5. Male pedipalps fronto-ventral view; 4. Male pedipalps, lateral view; 5. Female epigynum.

to be considered. Bites of $P$. tepidariorum can cause severe pain with a median duration of 16 hours, and in some cases systemic effects; which is very similar to the symptoms of steatodism (i.e. bites of false widows in the genus Steatoda Sundevall, 1833) (Isbister \& Gray, 2003). This, together with the synanthropic habits of this species increases the possibility of an accident, as occurs with other theridiid spiders (Faúndez \& Tellez, 2016a).

Finally, we believe probable that this species is present in the regions within the distributional gap in Chile. Therefore, more collecting is needed in order to elucidate the entire distribution of this species in the country. 


\section{LITERATURE CITED}

Faúndez, E. I., \& Téllez, F. (2016a). Primer registro de una mordedura de Steatoda nobilis (Thorell, 1875) (Arachnida: Araneae: Theridiidae) en Chile. Arquivos Entomolóxicos, 15, 237240.

Faúndez, E. I., \& Téllez, F. (2016b). Consideraciones sobre Steatoda nobilis (Thorell, 1875) en Chile. Biodiversity and Natural History, 2(1), 13-15.

Faúndez, E. I. (2009). Arañas (Arachnida: Araneae) peligrosas de la Región de Magallanes. Anales del Instituto de la Patagonia, 37(1), 127131.

Isbister, G. K., \& Gray, M. R. (2003). Effects of envenoming by comb-footed spiders of the genera Steatoda and Achaearanea (family Theridiidae: Araneae) in Australia. Journal of Toxicology - Clinical Toxicology, 41, 809819.
Levi H. W. (1955). The spider genera Coressa and Achaearanea in America north of Mexico (Araneae: Theridiidae). American Museum Novitates, 1718, 1-33.

Levi, H. W. (1967a). Cosmopolitan and Pantropical species of Theridiid spiders (Araneae: Theridiidae). Pacific Insects, 9(2), 175-186.

Levi, H. W. (1967b). The Theridiid spider fauna of Chile. Bulletin of the Museum of Comparative Zoology, 13(6), 1-20.

Sedgwick, W. C. (1973). New species, records and synonyms of Chilean Theridiid Spiders (Araneae, Theridiidae). Psyche, 80, 349-354.

Taucare-Ríos, A., Brescovit, D. A., \& Canals, M. (2013). Synanthropic spiders (Arachnida: Araneae) from Chile. Revista Ibérica de Aracnología, 23, 49-56.

World Spider Catalog. (2016). World Spider Catalog. Natural History Museum Bern, online at http://wsc.nmbe.ch, version 17.0, accessed on $23 / 010 / 2016$. 
